\title{
Turkish reference ranges for the left fetal modified myocardial performance index
}

\author{
Kadriye Yakut ${ }^{1 \oplus}$, Doğa Fatma Öcal ${ }^{2 \oplus}$, Filiz Öztürk ${ }^{2 \oplus}$, Merve Öztürk ${ }^{2 \oplus}$, \\ Cem Yaşar Sanhal ${ }^{3 \oplus}$, Şevki Çelen ${ }^{1 \oplus}$, Yaprak Üstün ${ }^{1 \oplus}$ \\ ${ }^{1}$ Department of Perinatology , Etlik Zubeyde Hanim Women's Health Teaching and Researching Hospital, Ankara; ${ }^{2}$ Department of \\ Perinatology, Turkish Ministry of Health, Ankara City Hospital, Ankara; ${ }^{3}$ Department of Perinatology, Akdeniz University Faculty of \\ Medicine, Antalya, Turkey.
}

\begin{abstract}
Background. This study aimed to assess fetal cardiac left ventricular function in healthy pregnant women by calculating the modified myocardial performance index (Mod-MPI) and to construct reference ranges for the Turkish population.
\end{abstract}

Methods. One-hundred-two randomly selected healthy singleton pregnant women ranging between 25 and 39 gestational weeks were included in the study. Left fetal Mod-MPI was measured for each pregnant woman. Women with chronic systemic diseases or fetuses with chromosomal or structural abnormalities were excluded from the study. Mitral valve (MV) and aortic valve (AoV) clicks were used as landmarks to define the following time periods that were used to calculate the Mod-MPI: isovolumetric contraction time (ICT), isovolumetric relaxation time (IRT), and ejection time (ET).

Results. The mean Mod-MPI was 0.42 \pm 0.10 . The mean IRT, ICT, and ET were $43.5 \pm 10.2,27.27 \pm 8.1$, and $170.5 \pm 16.9$, respectively. A significant correlation was found between Mod-MPI and gestational age, umbilical artery systolic/diastolic (UA S/D) ratio and the middle cerebral artery pulsatility index (MCA PI) values ( $\mathrm{r}=0.199$, $\mathrm{p}=0.047, \mathrm{r}=-0.328, \mathrm{p}=0.001$, and $\mathrm{r}=-0.0349, \mathrm{p}=0.001$, respectively)

Conclusions. The current study's results will be a reference for future studies, especially studies investigating pathological conditions that impact fetal cardiac function.

Key words: Modified myocardial performance index, healthy pregnancy, normal ranges, obstetrics.

The myocardial performance index (MPI) is a ratio obtained by Doppler ultrasound to assess heart functions. ${ }^{1} \mathrm{MPI}$ may be applied to the right or left ventricles of the heart. MPI is calculated by dividing the sum of the isovolumetric contraction time (ICT) and the isovolumetric relaxation time (IRT) by the ejection time (ET). ${ }^{1}$ Since there may be inter- and intraobserver variations, the MPI has been modified and valve clicks have been used as landmarks to optimize the measurements. ${ }^{2}$ The prognostic value of the MPI with other strain and remodeling indices

$\triangle$ Kadriye Yakut

yakutkadriye@hotmail.com

Received 27th December 2020, revised 15th March 2021, 28th March 2020, accepted 31st March 2021. has been studied in athletes with hypertrophic cardiomyopathy., In the present study, we hypothesized that conditions that influence fetal cardiac functions will result in changes in the MPI values. Fetal growth restriction, twin-twin transfusion syndrome, maternal diabetes, preeclampsia, fetal hydrops, fetal anemia, and cholestasis are examples of these conditions. $^{5-15}$ MPI values may be a guide for fetal interference and timing of the delivery in cases that affect cardiac function. However, it is important to ensure that the measurement of MPI is consistent and accurate. There is no universal reference range for an optimal MPI measurement methodology and no guidelines for normal values. Therefore, the present study aimed to measure MPI in healthy fetuses, 
and to standardize our own reference values and measurement method before conducting research on MPI measurements in relation to pathological conditions.

\section{Material and Methods}

\section{Study Design and Patient Selection}

Between November 2018 and February 2019, 102 randomly selected healthy singleton pregnant women ranging between 25 and 39 gestational weeks were included in the study. Ethical approval was obtained from the Zekai Tahir Burak Women's Health and Research Hospital's ethics committee before the study was conducted (Review board number: 21/2019). The study was performed in accordance with the ethical standards described in the original 1964 Declaration of Helsinki, and revised in 2013. Written informed consent was obtained from the patients included in the study. Pregnant women with a chronic systemic disease, such as diabetes, hypertension, heart disease, goiter, and kidney disease, or those with a history of drug use that would affect cardiac functions were excluded from participating in the study. The results of double-triple screening tests, detailed ultrasonography, and oral glucose loading tests were evaluated. Pregnant women with low risk and normal screening results were included in the study.

\section{Mod-MPI Measurement}

All ultrasonographic measurements were performed by one obstetrician, who had at least 10 years of experience. The observer evaluated each patient and obtained three measurements. The mean of all measurements was recorded.

Ultrasonographic measurements were performed using a Voluson 730 Expert (GE Medical Systems, Waukesha, WI, USA) ultrasound machine and 2-7 $\mathrm{MHz}$ curvilinear probe during the absence of fetal movements. Both mechanical and thermal indices were kept below 1.0. Gestational age (GA) was calculated according to the first day of the last menstrual period, and it was confirmed by the first-trimester crown rump length (CRL) measurement. Initially, fetal biometry was performed. Biparietal diameter (BPD), head circumference (HC), abdominal circumference $(\mathrm{AC})$, femur length (FL), and estimated fetal weight (EFW) were evaluated and recorded. Subsequently, amniotic fluid index, umbilical artery (UA) Doppler, and localization and structure of the placenta were examined, and all the measurements were recorded. Fetal echocardiographic measurements were performed after it was determined that the patient had no obstetric pathology.

Doppler and fetal echocardiography were performed based on the International Society of Ultrasound and Obstetrics and Gynecology (ISUOG) Practice Guidelines. ${ }^{16}$ The modified MPI (Mod-MPI) method was used to measure fetal left ventricular MPI, as described by Hernandez-Andrade et al. ${ }^{2}$ Prior to the ModMPI measurement, the apical four-chamber view of the heart was obtained. The women for whom we were unable to view a favorable fetal position to obtain an optimal cross-section were evaluated at different times. The Doppler sample was opened at 3-5 $\mathrm{mm}$ and placed at the lateral wall of the ascending aorta to include both the mitral valve (MV) and the aortic valve $(\mathrm{AoV})$. The insonation angle was maintained below 15 degrees. The wall motion filter was calibrated at $300 \mathrm{~Hz}$, and the Doppler sweep velocity was $5 \mathrm{~cm} / \mathrm{s}$. Doppler gain was lowered in order to clearly see the valve clicks. The clicks of the opening and closing of the AoV and the MV were obtained. Early ventricular filling (E) and active atrial filling (A) waves were viewed. ICT was described as the time interval beginning with the closing of the MV and ending with the opening of the AoV. IRT was described as the time interval beginning with the closing of the AoV and ending with the opening of the MV. ET was described as the time interval beginning with the opening of the $\mathrm{AoV}$ and ending with the closing of the AoV (Fig. 1). Mod-MPI was calculated by using the following formula: (ICT+IRT)/ET. 


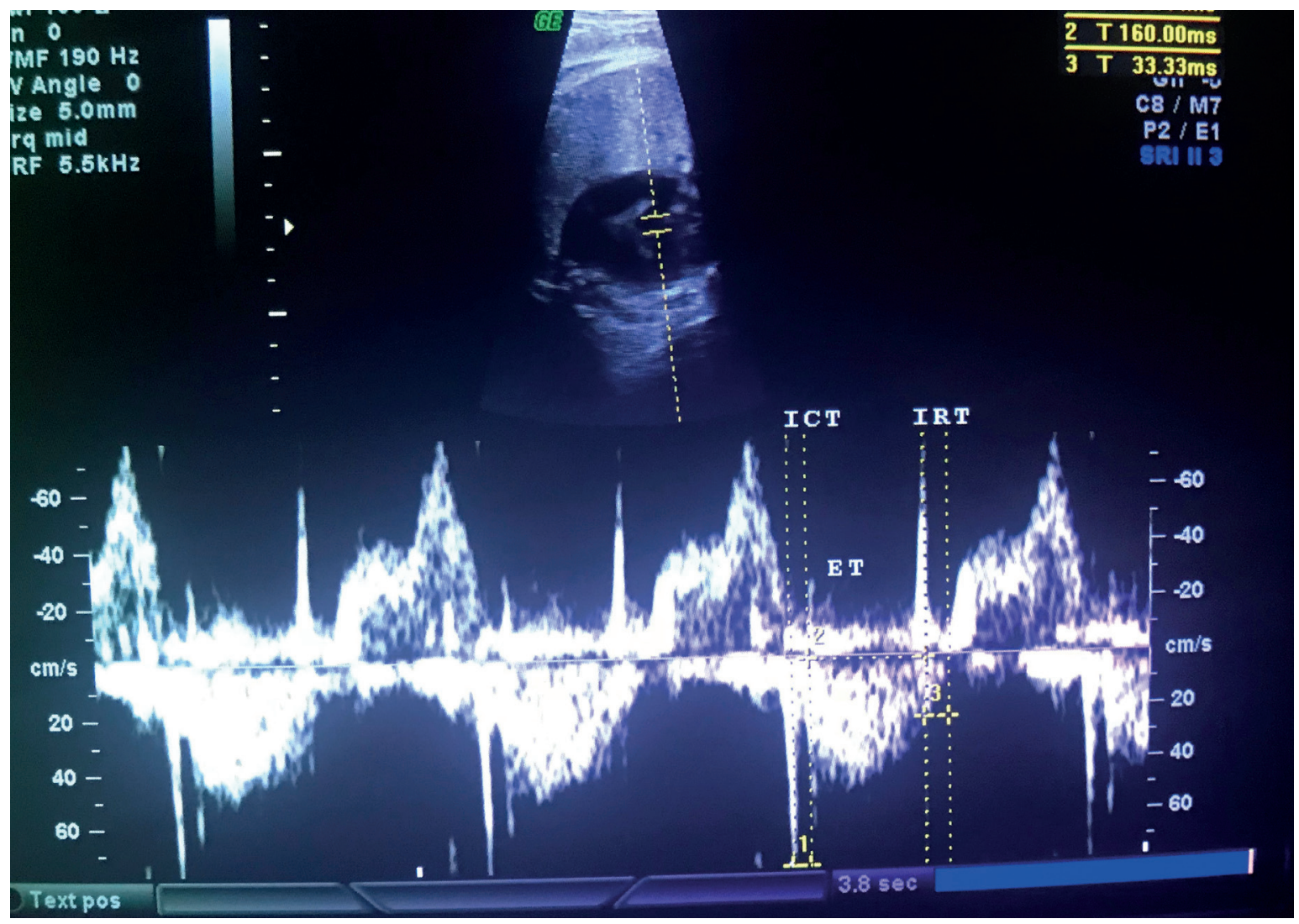

Fig. 1. Doppler trace of isovolumetric contraction time (ICT), ejection time (ET), isovolumetric relaxation time (IRT), and E/A wave peak velocities.

All the results and demographic characteristics, such as age, gravidity, parity, number of abortions, number of living children, and gestational week were recorded.

\section{Statistical Analysis}

All the statistical analyses were performed using SPSS (IBM SPSS Statistics for Windows, version 21.0, released 2012, Armonk, NY, USA: IBM Corp.). Descriptive statistics were reported as mean \pm standard deviation (SD), median (minimum-maximum), and mean $+95 \%$ reference interval. Spearman's correlation test was used to analyze the correlations between the parameters. $\mathrm{P}<0.05$ was considered to be statistically significant.

\section{Results}

According to our results, the median age, body mass index (BMI), gravidity, parity, number of living children, number of abortions, EFW, and gestational week were 27 (20-43), 28.7 (19.644.4), 2 (1-6), 1 (0-4), 0 (0-4), 0 (0-3), 2300 (7164030), 34.6 (25.4-39.1), respectively.

Table I shows the ultrasonographic measurements for the pregnant women. Accordingly, the mean Mod-MPI was $0.42 \pm 0.10$ while the mean IRT, ICT, and ET were $43.5 \pm 10.2$, $27.27 \pm 8.1$, and $170.5 \pm 16.9$, respectively.

The results for the normal gestational ranges in the Turkish population are shown in Figure 2 as scatter plots, with the estimated mean and 
Table I. Ultrasonographic measurements of the pregnant women in the study.

\begin{tabular}{lcc}
\hline & Mean \pm SD & $\begin{array}{c}\text { Median } \\
(\text { Min-Max })\end{array}$ \\
\hline UA-Doppler RI & $1.09 \pm 0.34$ & $0.6(0.2-4.5)$ \\
UA-Doppler S/D & $2.66 \pm 0.30$ & $2.6(1.3-4.2]$ \\
UA-Doppler PI & $0.98 \pm 0.38$ & $1.0(0.3-2.7)$ \\
MVP & $47.75 \pm 31.30$ & $50.0(0.0-76.0)$ \\
ICT & $27.27 \pm 8.10$ & $26(12-48)$ \\
IRT & $43.5 \pm 10.20$ & $44(23-70)$ \\
ET & $170.4 \pm 16.90$ & $173(123-213)$ \\
Mod-MPI & $0.42 \pm 0.10$ & $0.4(0.21-0.67)$ \\
MCA-PI & $1.97 \pm 0.69$ & $1.8(0.97-3.7)$ \\
UtA-PI & $3.82 \pm 0.27$ & $0.82(0.49-2.41)$ \\
DV-PI & $0.68 \pm 0.41$ & $0.63(0.12-1.79)$ \\
TCD & $41.02 \pm 6.65$ & $42(26.7-52)$
\end{tabular}

UA: Umbilical artery, RI: Resistance index, S/D: Systole/ diastole, PI: Pulsatility index, ICT: Isovolumetric contraction time, IRT: Isovolumetric relaxation time, ET: Ejection time, Mod-MPI: Modified myocardial performance index, MCA: Middle cerebral artery, UtA: Uterine artery,

DV: Ductus venosus, TCD: Trans cerebellar diameter, MVP: Maximum vertical amniotic pocket percentile curves for ICT, IRT, ET, and ModMPI. ICT and IRT were constant during the pregnancies, while ET decreased and Mod-MPI increased throughout the gestational period.

Spearman's correlation test was used to assess the relationship between the parameters (Table II). The correlation coefficient analysis results revealed that there was a significant correlation between Mod-MPI and GA, and UA systolic/diastolic (UA S/D) ratio and the middle cerebral artery pulsatility index (MCA PI) values $(\mathrm{r}=0.199, \mathrm{p}=0.047, \mathrm{r}=-0.328, \mathrm{p}=0.001$, and $\mathrm{r}=-0.0349$, $\mathrm{p}=0.001$, respectively) (Fig. 3). ModMPI increased with advanced GA; moreover, Mod-MPI decreased as UA S/D and MCA increased. However, no statistically significant correlation was found between Mod-MPI and the women's age, EFW, BMI, UA Doppler PI/ RI (resistance index), ductus venosus (DV)-PI, and uterine artery (UtA)-PI values ( $p>0.05)$. A negative correlation was found between ET and gestational week $(\mathrm{r}=0.238, \mathrm{p}=0.018)$ (Fig. 4). All of the UA doppler parameters (S/D, PI, and RI)
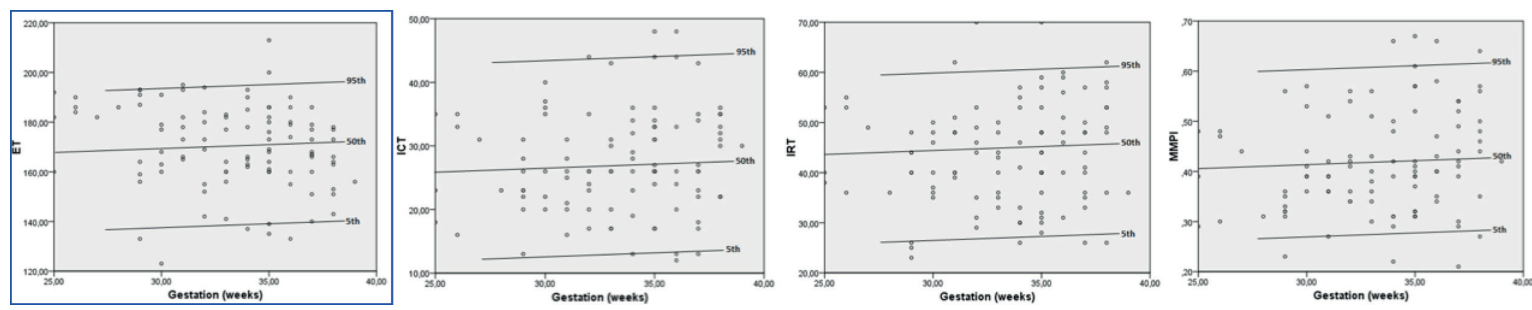

Fig. 2. Results for normal gestational ranges in the study's Turkish population for ICT, IRT, ET, and Mod-MPI.
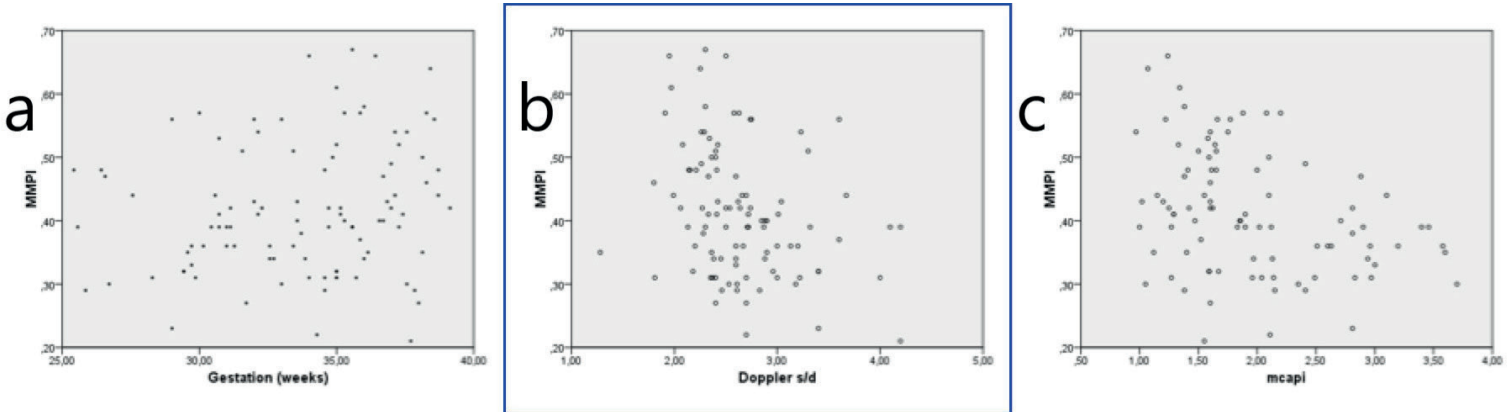

Fig. 3. The correlation between Mod-MPI and GA, UA S/D, and MCI PI. 
Table II. The relationship between the study's parameters*.

\begin{tabular}{|c|c|c|c|c|c|}
\hline & & Mod-MPI & ICT & IRT & ET \\
\hline \multirow[t]{2}{*}{ Age (year) } & $\mathrm{r}$ & -0.021 & -0.071 & 0.123 & 0.086 \\
\hline & $\mathrm{p}$ & 0.849 & 0.511 & 0.257 & 0.427 \\
\hline \multirow[t]{2}{*}{ GA (week) } & $\mathrm{r}$ & 0.199 & 0.117 & 0.131 & -0.236 \\
\hline & $\mathrm{p}$ & 0.047 & 0.245 & 0.194 & 0.018 \\
\hline \multirow[t]{2}{*}{ EFW } & $\mathrm{r}$ & 0.178 & 0.077 & 0.170 & -0.204 \\
\hline & $\mathrm{p}$ & 0.097 & 0.473 & 0.114 & 0.056 \\
\hline \multirow[t]{2}{*}{ BMI } & $\mathrm{r}$ & 0.078 & -0.045 & 0.027 & -0.071 \\
\hline & $\mathrm{p}$ & 0.462 & 0.670 & 0.802 & 0.500 \\
\hline \multirow[t]{2}{*}{ UA-S/D } & $\mathrm{r}$ & -0.328 & -0.131 & -0.421 & 0.169 \\
\hline & $\mathrm{p}$ & 0.001 & 0.198 & 0.000 & 0.096 \\
\hline \multirow[t]{2}{*}{ UA-PI } & $\mathrm{r}$ & -0.181 & 0.028 & -0.303 & 0.067 \\
\hline & $\mathrm{p}$ & 0.080 & 0.790 & 0.003 & 0.520 \\
\hline \multirow[t]{2}{*}{ UA-RI } & $\mathrm{r}$ & -0.200 & -0.085 & -0.316 & 0.092 \\
\hline & $\mathrm{p}$ & 0.053 & 0.413 & 0.002 & 0.376 \\
\hline \multirow[t]{2}{*}{ MCA-PI } & $\mathrm{r}$ & -0.349 & -0.339 & -0.149 & 0.192 \\
\hline & $\mathrm{p}$ & 0.001 & 0.001 & 0.158 & 0.068 \\
\hline \multirow[t]{2}{*}{ DV-PI } & $\mathrm{r}$ & 0.160 & 0.210 & 0.066 & 0.007 \\
\hline & $\mathrm{p}$ & 0.261 & 0.139 & 0.646 & 0.961 \\
\hline \multirow[t]{2}{*}{ UtA-PI } & $\mathrm{r}$ & -0.206 & -0.121 & -0.162 & 0.091 \\
\hline & $\mathrm{p}$ & 0.065 & 0.282 & 0.149 & 0.420 \\
\hline \multirow[t]{2}{*}{ TCD } & $\mathrm{r}$ & 0.109 & 0.154 & -0.060 & -0.219 \\
\hline & $\mathrm{p}$ & 0.390 & 0.226 & 0.639 & 0.081 \\
\hline
\end{tabular}

*Spearman correlation test was used. GA: Gestational Age, EFW: Estimated Fetal Weight, BMI: Body Mass Index, UA-S/D: Umbilical artery systole/diastole, UA-PI: Umbilical artery Pulsatility Index, RI: Resistance Index, MCA: Middle Cerebral Artery, DV: Ductus Venosus, UtA: Uterine artery, TCD: Trans cerebellar diameter, Mod-MPI: Modified myocardial performance index, ICT: Isovolumetric contraction time, IRT: Isovolumetric relaxation time, ET: Ejection time.

were found to have a negative correlation with IRT $(\mathrm{r}=-0.421, \mathrm{p}=0.000, \mathrm{r}=-0.303, \mathrm{p}=0.003$, and $\mathrm{r}=-$ $0.316, \mathrm{p}=0.002$, respectively) (Fig. 5). A negative correlation was also found between ICT and MCA-PI (Fig. 6).

Table III shows the means and the $95 \%$ reference intervals for the Mod-MPI, ICT, IRT, and ET values based on the gestational week. There was an increase in the Mod-MPI from 25 to 39 weeks of gestation, with means \pm SD of $0.37 \pm 0.087$ at 25 weeks and a mean of $0.42 \pm 0.11$ at 39 weeks.

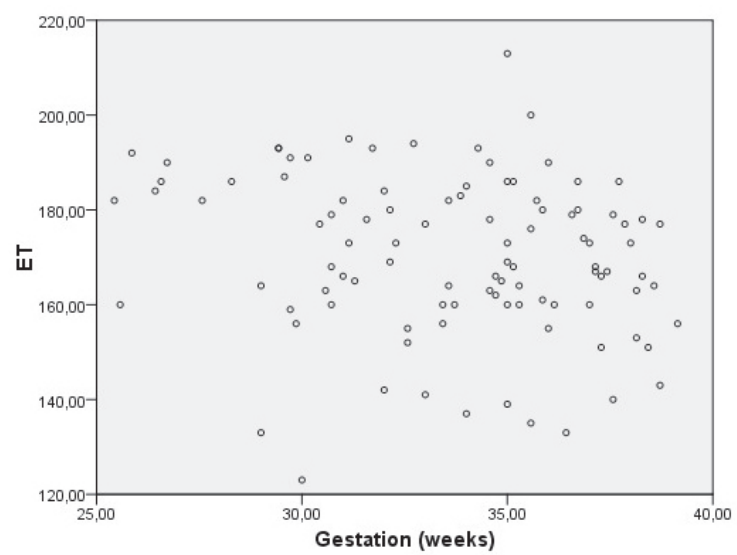

Fig. 4. The correlation between ET and GA. 
Table III. Means and 95\% reference intervals for Mod-MPI, ICT, IRT and ET throughout pregnancy.

\begin{tabular}{lcccccccc}
\hline $\begin{array}{l}\text { Gestational } \\
\text { age weeks }\end{array}$ & $\begin{array}{c}\text { Mod-MPI } \\
\text { mean }\end{array}$ & $\begin{array}{c}\text { Mod-MPI } \\
\text { 95\% reference } \\
\text { interval }\end{array}$ & $\begin{array}{c}\text { ICT } \\
\text { mean }\end{array}$ & $\begin{array}{c}\text { ICT 95\% } \\
\text { reference } \\
\text { interval }\end{array}$ & $\begin{array}{c}\text { IRT } \\
\text { mean }\end{array}$ & $\begin{array}{c}\text { IRT 95\% } \\
\text { reference } \\
\text { interval }\end{array}$ & $\begin{array}{c}\text { ET } \\
\text { mean }\end{array}$ & $\begin{array}{c}\text { ET 95\% } \\
\text { reference } \\
\text { interval }\end{array}$ \\
\hline 25 & 0.39 & $0.15-0.62$ & 25.3 & $3.6-47.0$ & 43.7 & $23.4-63.9$ & 178.0 & $137.3-218.7$ \\
26 & 0.42 & $0.17-0.67$ & 28.0 & $2.1-53.9$ & 48.0 & $22.1-73.9$ & 186.7 & $179.1-194.3$ \\
27 & 0.44 & $0.18-0.67$ & 31.0 & $4.2-42.6$ & 49.0 & $23.4-82.1$ & 182.0 & $142.0-196$ \\
28 & 0.31 & $0.13-0.53$ & 23.0 & $17.2-32.0$ & 36.0 & $25.4-40.2$ & 186.0 & $175.2-192.4$ \\
29 & 0.35 & $0.27-0.43$ & 23.3 & $18.7-27.8$ & 36.3 & $27.9-44.6$ & 172.0 & $153.4-190.6$ \\
30 & 0.44 & $0.37-0.51$ & 30.9 & $23.5-38.3$ & 41.7 & $36.0-47.4$ & 165.9 & $145.8-185.9$ \\
31 & 0.39 & $0.32-0.45$ & 23.9 & $19.1-28.6$ & 46.8 & $39.3-54.5$ & 178.9 & $167.8-189.9$ \\
32 & 0.43 & $0.35-0.50$ & 26.9 & $19.6-34.1$ & 44.6 & $33.4-55.8$ & 168.6 & $153.8-183.4$ \\
33 & 0.41 & $0.34-0.48$ & 26.3 & $19.0-33.5$ & 41.1 & $35.9-46.3$ & 165.4 & $177.5-135.8$ \\
34 & 0.40 & $0.29-0.50$ & 26.7 & $21.0-32.3$ & 41.2 & $32.0-50.4$ & 171.0 & $157.5-184.5$ \\
35 & 0.43 & $0.37-0.49$ & 29.9 & $25.5-34.4$ & 43.8 & $37.5-50.0$ & 172.0 & $161.3-182.7$ \\
36 & 0.45 & $0.36-0.55$ & 27.5 & $16.4-38.6$ & 48.9 & $40.6-57.2$ & 169.6 & $153.7-185.6$ \\
37 & 0.41 & $0.34-0.49$ & 25.8 & $19.9-31.7$ & 41.6 & $35.7-47.6$ & 166.7 & $158.0-175.4$ \\
38 & 0.42 & $0.31-0.54$ & 30.7 & $28.6-32.7$ & 36.1 & $40.3-57.9$ & 156.0 & $143.8-164.2$ \\
39 & 0.47 & $0.39-0.56$ & 30.0 & $26.6-34.7$ & 49.1 & $40.3-57.9$ & 163.1 & $153.8-172.4$ \\
\hline
\end{tabular}

Mod-MPI: Modified myocardial performance index, ICT: Isovolumetric contraction time, IRT: Isovolumetric relaxation time, ET: Ejection time.
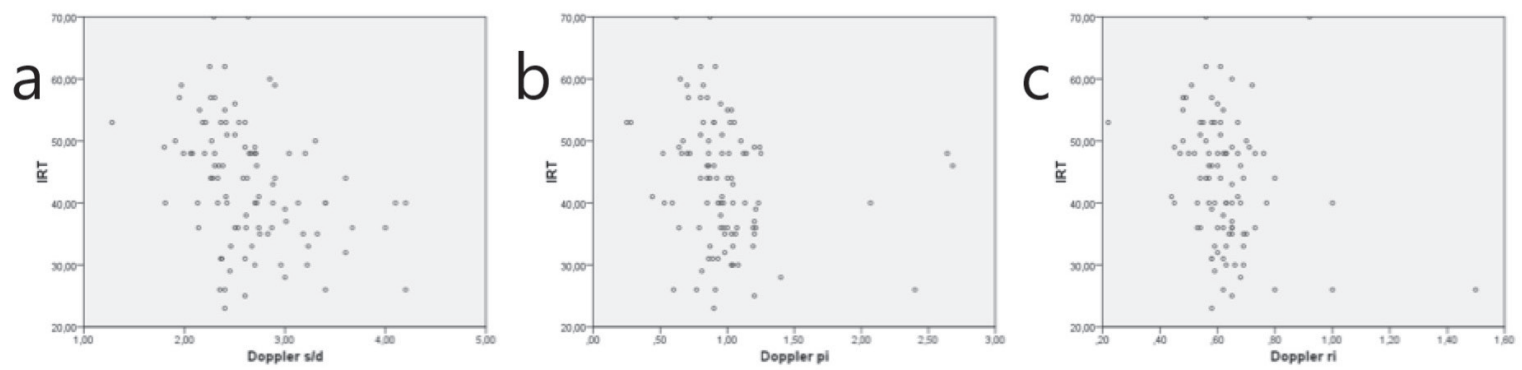

Fig. 5. The correlation between IRT and UA S/D, PI, and RI.

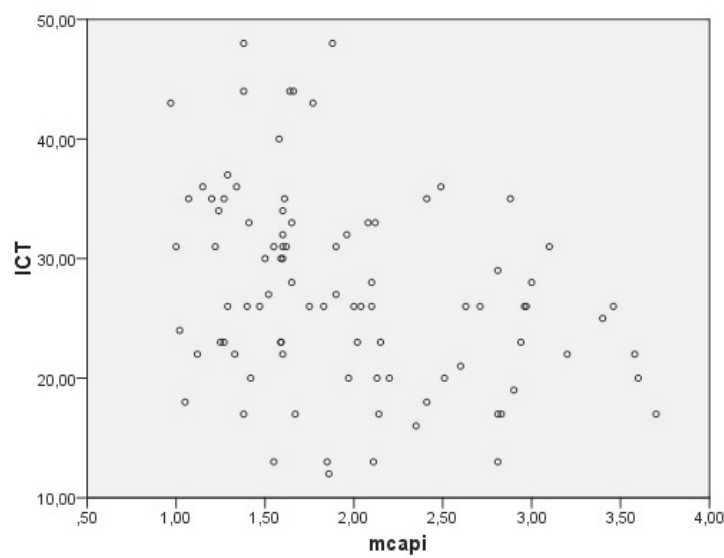

Fig. 6. The correlation between ICT and MCA PI. 


\section{Discussion}

The main findings of this study were:

1. The normal reference of Mod-MPI was 0.4 (0.21-0.67).

2. There was a positive correlation between the Mod-MPI values and GA. The ModMPI values significantly increased with GA.

3. There was a negative correlation between the Mod-MPI values and UA S/D and MCA-PI.

There are several ways to evaluate cardiac functions during the intrauterine period. MPI is one of the most common methods used to evaluate cardiac functions, globally. Conditions that disturb cardiac systolic functions result in the lengthening of the ICT and shortening of the ET. Thus, the systolic dysfunction results in prolonging the MMPI values. Previously we investigated the utility of Mod-MPI in fetal growth restriction (FGR). There was no difference between the groups in terms of Mod-MPI values. MPI values in healthy fetuses were $0,4(0,3-0,7)$. However, IRT values, the earliest influenced component of MPI, were significantly lower in the FGR group than in the control group. ${ }^{17}$ Another study performed by Kir et al. ${ }^{18}$ investigated the importance of MPI in children diagnosed with isolated ventricular septal defect (VSD). The MPI values were found to be significantly higher in children with VSD than in healthy children, and the mean MPI values in healthy children were $0,26 \pm 0,005$. This average value is lower when compared to fetal MPI values; it may be related to changes in fetal cardiac geometry and the myocardium's functional capacity in the intrauterine environment.

We found a negative correlation between UA S/D and the Mod-MPI and IRT values. IRT is an important component of fetal cardiac function. Disruption of IRT results in reduced calcium uptake and a reduction in fetal cardiac function. Moreover, IRT is the earliest influenced component of MPI in cases of pathological conditions. The pathological increase in UA S/D means a disruption of blood supply to the fetus. Previous studies have demonstrated that pathological conditions that could influence cardiac functions also alter the Mod-MPI values. ${ }^{5-15}$ In the present study, all of the UA S/D values were in the normal ranges based on GA. Therefore, we could not interpret this result objectively.

The present study showed that the normal Mod-MPI measurements of our pregnant population (0.4 [0.21-0.67]) were consistent with the reference intervals reported in previous studies. ${ }^{15-19}$ Additionally, in our study the ModMPI values increased with GA, which is similar to the results reported by Cruz-Martinez et al. ${ }^{19}$ who found a positive correlation between ModMPI and GA.

The literature reports a wide range for the mean MPI values. Although some previous studies advocate that the mean MPI is a constant value throughout pregnancy ${ }^{20-22}$, it has also been reported that the MPI values are GAdependent. ${ }^{23}$ Moreover, some studies have demonstrated that the MPI values decrease with GA..$^{24,25}$ This inconsistency could be due to differences in the techniques used to measure the MPI. The ultrasound device settings are also important. Hernandez-Andrade et al. ${ }^{2}$ used a Mod-MPI measurement technique with an insonation angle ranging between 0-30 degrees and a sweep speed of $15 \mathrm{~cm} / \mathrm{s}$. In the present study, we used an insonation angle ranging between 0-15 degrees and a sweep speed of 5 $\mathrm{cm} / \mathrm{s}$. Using a high sweep speed ensures optimal magnification for the correct placement of the caliper when obtaining the measurements. We increased the sweep speed to $5 \mathrm{~cm} / \mathrm{sn}$, as reported by Sanhal et al. ${ }^{13}$

The Doppler sample placement point is another challenge of Mod-MPI measurements. ${ }^{26}$ Applying valve clicks when measuring MPI may decrease the inter- and intraobserver variations. However, valve clicks also have a thickness, so Mod-MPI values may be altered 
if they are measured from the beginning of the valve clicks. Furthermore, original or reflected valve clicks may be used for the measurement. Although the beginning points and the end points are different, the peaks of the original $\mathrm{MV}$ and AoV closure clicks match the peaks of the reflected valve clicks. In the present study, we used the peak point of the clicks to prevent variation in the caliper placement due to the click interval. Similarly, Meriki and Welsh suggested using the peaks of the clicks to obtain the MPI measurements. ${ }^{27}$ Other authors have also suggested using the beginning points of the clicks to place the calipers. ${ }^{15,19,27}$

To calculate the MPI, we preferred using the left Mod-MPI measurement. However, the use of the right MPI measurement has also been reported..$^{28}$ Paytoncu et al. ${ }^{29}$ also evaluated fetal cardiac function via measuring MPI from the fetal left and right ventricles and tricuspid and mitral annular plane systolic excursions (TAPSE and MAPSE). They included 152 fetuses in their second and third trimesters in the study. Similar to us, they found the left ventricle mean MPI value as $0,47 \pm 0,16$. However, in this study, they did not detect a difference between the gestational week's progression and the MPI values. ${ }^{29}$ Theoretically, the right MPI measurement seems to be more prudent, since the fetal heart is thought to be right dominant during the intrauterine period. ${ }^{26,30}$ Although evaluation of the right ventricle provides early findings on cardiac dysfunction, MPI assessment requires two different planes for right ventricle pulmonary and tricuspid valve measurements. This makes it difficult to evaluate the right ventricle. However, the AoV and MV components of the left ventricle can be easily determined in the same section, and a Doppler examination can be performed. Moreover, more studies have reported on left ventricular MPI data than right ventricle MPI data. Nevertheless, reports on the clinical applications of fetal left MPI are controversial.

Previous studies have reported on the reproducibility of Mod-MPI measurements, and the reproducibility rate was found to be low when the GA was less than 27 weeks. In earlier GA weeks, the interobserver correlation rate also decreases. However, in the late periods of pregnancy, both measurement repeatability and interobserver correlation increase. This may be due to the relative increase in the size of the fetal heart, and, thus, to a more accurate placement of the Doppler caliper. ${ }^{26}$

If MPI is to be used as a useful clinical parameter, an acceptable reference range for normal fetuses should be presented. ${ }^{27}$ Consequently, it is necessary to establish a standard for the factors that will cause variations, such as the device, the device settings, and the caliper placement technique.

To minimize the interobserver differences and obtain a standardized method with possible repeatability and reliability, automated MPI measurement techniques have been researched, and their routine usability has been communicated. With the introduction of routine use in automated methods, the relationship of MPI with fetal pathologies will be understood more clearly in the future. ${ }^{31,32}$

Previous studies have reported that a learning process is required in order to perform accurate MPI measurements. For example, CruzMartinez et al. ${ }^{30}$ reported average numbers related to the completion of the learning process associated with left Mod-MPI measurements, such as 42 for ET, 77 for ICT, and 83 for IRT.

Before conducting this study, the obstetrician who performed the MPI measurements had previously measured, on average, 100 healthy pregnant women; however, these measurements were not included in the study.

In conclusion, this study's results contribute to the field in several ways. We generated normal gestational reference ranges for Mod-MPI for the Turkish population. We used an objective method for caliper placement and ultrasound machine settings. The study's sample size was relatively larger than the sample sizes of some previous studies. ${ }^{21,23,24,26}$ These results will be a reference for future studies, especially those 
investigating the pathological conditions that impact fetal cardiac functions.

\section{Acknowledgements}

None.

\section{Author contributions}

The authors confirm contribution to the paper as follows: study conception and design: KY, DFÖ; data collection: KY, DFÖ; analysis interpetation of results: $\mathrm{MO}, \mathrm{FO}, \mathrm{CS}$; draft manuscript preperation: KY, YÜ, ŞÇ. All authors reviewed the results and approved the final version of the manuscript.

\section{Ethical approval}

Ethical approval was obtained from the Zekai Tahir Burak Women's Health and Research Hospital's ethics committee before the study was conducted (Review board number: 21/2019).

\section{Source of funding}

This research received no specific grant from any funding agency, commercial or not-forprofit sectors.

\section{Conflict of interest}

The authors report no conflicts of interest.

\section{REFERENCES}

1. Tei C. New non-invasive index for combined systolic and diastolic ventricular function. J Cardiol 1995; 26: 135-136.

2. Hernandez-Andrade E, Lopez-Tenorio J, FigueroaDiesel $\mathrm{H}$, et al. A modified myocardial performance (Tei) index based on the use of valve clicks improves reproducibility of fetal left cardiac function assessment. Ultrasound Obstet Gynecol 2005; 26: 227-232. https://doi.org/10.1002/uog.1959
3. Kobayashi Y, Moneghetti KJ, Bouajila S, et al. Time based versus strain based myocardial performance indices in hypertrophic cardiomyopathy, the merging role of left atrial strain. Eur Heart J Cardiovasc Imaging 2019; 20: 334-342. https://doi. org/10.1093/ehjci/jey097

4. Duyuler S. Myocardial performance in elite athletes: the role of homocysteine, iron, and lipids. Med Sci Monit 2019; 25: 1194-1203. https://doi.org/10.12659/ MSM.913561

5. Crispi F, Hernandez-Andrade E, Pelsers MM, et al. Cardiac dysfunction and cell damage across clinical stages of severity in growth-restricted fetuses. Am J Obstet Gynecol 2008; 199: 254.e1-254.e8. https://doi. org/10.1016/j.ajog.2008.06.056

6. Henry A, Alphonse J, Tynan D, Welsh AW. Use of the fetal Myocardial Performance Index in assessment and management of the Small for Gestational Age fetus: a cohort and nested case-control study. Ultrasound Obstet Gynecol 2018; 51: 225-235. https:// doi.org/10.1002/uog.17476

7. Chawengsettakul S, Russameecharoen K, Wanitpongpan P. Fetal cardiac function measured by myocardial performance index of small-forgestational age fetuses. J Obstet Gynaecol Res 2015; 41: 222-228. https://doi.org/10.1111/jog.12508

8. Bhorat IE, Bagratee JS, Pillay M, Reddy $T$. Determination of the myocardial performance index in deteriorating grades of intrauterine growth restriction and its link to adverse outcomes. Prenat Diagn 2015; 35: 266-273. https://doi.org/10.1002/ pd. 4537

9. Raboisson MJ, Fouron JC, Lamoureux J, et al. Early intertwin differences in myocardial performance during the twin-to-twin transfusion syndrome. Circulation 2004; 110: 3043-3048. https://doi. org/10.1161/01.CIR.0000146896.20317.59

10. Van Mieghem T, Klaritsch P, Done E, et al. Assessment of fetal cardiac function before and after therapy for twin-to-twin transfusion syndrome. Am J Obstet Gynecol 2009; 200: 400.e1-400.e7. https://doi. org/10.1016/j.ajog.2009.01.051

11. Gapp-Born E, Sananes N, Guerra F, et al. Predictive value of cardiovascular parameters in stages 1 and 2 of twin-to-twin transfusion syndrome. Prenat Diagn 2014; 34: 908-914. https://doi.org/10.1002/pd.4393

12. Russell NE, Foley M, Kinsley BT, Firth RG, Coffey M, McAuliffe FM. Effect of pregestational diabetes mellitus on fetal cardiac function and structure. Am J Obstet Gynecol 2008; 199: 312.e1-312.e7. https://doi. org/10.1016/j.ajog.2008.07.016 
13. Sanhal CY, Daglar HK, Kara O, Uygur D, Yucel A. Assessment of fetal myocardial performance index in women with pregestational and gestational diabetes mellitus. J Obstet Gynaecol Res 2017; 43: 6572. https://doi.org/10.1111/jog.13174

14. Bhorat I, Pillay M, Reddy T. Determination of the fetal myocardial performance index in women with gestational impaired glucose tolerance and to assess whether this parameter is a possible prognostic indicator of adverse fetal outcome. J Matern Fetal Neonatal Med 2018; 31: 2019-2026. https://doi.org/1 0.1080/14767058.2017.1334047

15. Hernandez-Andrade E, Figueroa-Diesel H, Kottman $C$, et al. Gestational-age-adjusted reference values for the modified myocardial performance index for evaluation of fetal left cardiac function. Ultrasound Obstet Gynecol 2007; 29: 321-325. https://doi. org/10.1002/uog.3947

16. International Society of Ultrasound in Obstetrics and Gynecology, Carvalho JS, Allan LD, et al. ISUOG Practice Guidelines (updated): sonographic screening examination of the fetal heart. Ultrasound Obstet Gynecol 2013; 41: 348-359. https://doi. org/10.1002/uog.12403

17. Öcal DF, Yakut K, Öztürk FH, et al. Utility of the modified myocardial performance index in growthrestricted fetuses. Echocardiography 2019; 36: 18951900. https://doi.org/10.1111/echo.14489

18. Kır M, Ünal M, Saylam GS, Karadas U, Sahin M. Ventriküler septal defektli çocuklarda sol ventrikül fonksiyonlarının miyokardiyal performans indeksi (Tei indeksi) kullanılarak değerlendirilmesi. Dokuz Eylül Üniversitesi Tıp Fakültesi Dergisi 2018; 22: 113-119.

19. Cruz-Martinez R, Figueras F, Bennasar M, et al. Normal reference ranges from 11 to 41 weeks' gestation of fetal left modified myocardial performance index by conventional Doppler with the use of stringent criteria for delimitation of the time periods. Fetal Diagn Ther 2012; 32: 79-86. https://doi.org/10.1159/000330798

20. Clur SA, Oude Rengerink K, Mol BW, Ottenkamp J, Bilardo CM. Fetal cardiac function between 11 and 35 weeks' gestation and nuchal translucency thickness. Ultrasound Obstet Gynecol 2011; 37: 4856. https://doi.org/10.1002/uog.8807

21. Friedman D, Buyon J, Kim M, Glickstein JS. Fetal cardiac funtion assessed by Doppler myocardial performance index (Tei index). Ultrasound Obstet Gynecol 2003; 21: 33-36. https://doi.org/10.1002/ uog.11

22. Van Mieghem T, Gucciardo L, Lewi $P$, et al. Validation of the fetal myocardial performance index in the second and third trimesters of gestation. Ultrasound Obstet Gynecol 2009; 33: 58-63. https:// doi.org/10.1002/uog.6238
23. MacDonald TM, Robinson AJ, Walker SP, Hui S. Prospective longitudinal assessment of the fetal left modified Myocardial Performance Index. J Matern Fetal Neonatal Med 2017; 32: 760-767. https://doi.org /10.1080/14767058.2017.1391777

24. Meriki N, Welsh AW. Development of Australian reference ranges for the left fetal modified myocardial performance index and the influence of caliper location on time interval measurement. Fetal Diagn Ther 2012; 32:87-95. https://doi. org $/ 10.1159 / 000334133$

25. Leung V, Avnet H, Henry A, Wang J, Redmond S, Welsh AW. Automation of the Fetal Right Myocardial Performance Index to Optimise Repeatability. Fetal Diagn Ther2018; 44: 28-35. https://doi. org/10.1159/000478928

26. Mielke G, Benda N. Cardiac output and central distribution of blood flow in the human fetus. Circulation 2001; 103: 1662-1668. https://doi. org/10.1161/01.CIR.103.12.1662

27. Rasanen J, Wood DC, Weiner S, Ludomirski A, Huhta JC. Role of the pulmonary circulation in the distribution of human fetal cardiac output during the second half of pregnancy. Circulation 1996; 94: 1068-1073. https://doi.org/10.1161/01.CIR.94.5.1068

28. Mahajan A, Henry A, Meriki N, et al. The (pulsedwave) Doppler fetal myocardial performance index: technical challenges, clinical applications and future research. Fetal Diagn Ther 2015; 38: 1-13. https://doi. org/10.1159/000363181

29. Paytoncu S. Conventional Doppler myocardial performance index, tricuspid and mitral annular plane systolic excursions in the assessment of fetal heart functions. Perinatal Journal 2018; 26: 117-123. https://doi.org/10.2399/prn.18.0263004

30. Cruz-Martinez R, Figueras F, Jaramillo JJ, et al. Learning curve for Doppler measurement of fetal modified myocardial performance index. Ultrasound Obstet Gynecol 2011; 37: 158-162. https:// doi.org/10.1002/uog.7765

31. Maheshwari P, Henry A, Welsh AW. The fetal modified myocardial performance index: is automation the future? Biomed Res Int 2015; 2015: 215910. https://doi.org/10.1155/2015/215910

32. Kim SM, Ye SY. Evaluation of the fetal left ventricular myocardial performance index (MPI) by using an automated measurement of doppler signals in normal pregnancies. Diagnostics (Basel) 2021; 11: 358. https://doi.org/10.3390/diagnostics11020358 